\title{
Fisheries change spawning ground distribution of northeast Arctic cod
}

\author{
Anders Frugård Opdal* \\ Department of Biology, University of Bergen, PO Box 7803, \\ N-5020 Bergen, Norway \\ *anders.opdal@bio.uib.no
}

Prior to the 1920s, the northeast Arctic (NA) cod were caught at spawning grounds ranging from the southernmost to the northernmost parts of the Norwegian coast, but have for the last $50 \mathrm{yr}$ mainly been caught around the Lofoten archipelago and northwards. The NA cod have their feeding and nursery grounds in the Barents Sea, and migrate south towards the Norwegian coast in the winter to spawn. This study uses commercial fisheries' data from landing ports along the entire Norwegian coast during the period 1866-1969 as evidence of long-term truncation and northerly shift of spawning grounds. Nearly all spawning grounds south of Lofoten have been abandoned, while an increasing proportion of the spawning stock only uses the northernmost areas of the Norwegian coast, Troms and Finnmark. The truncation can hardly be attributed to long-term climatic variations, but may result from an intensive size-selective trawl fishery in the Barents Sea causing a sudden increase in fishing mortality, probably altering the size structure and migratory capacity of the stock.

Keywords: northeast Arctic cod; fisheries; spawning migration

\section{INTRODUCTION}

Much concern has been raised on how organisms respond to climate variability, climate change and human interventions such as harvesting (e.g. Walther et al. 2002; Jørgensen et al. 2007), and long time series are often our main source of information about long-term ecological changes. The northeast Arctic (NA) cod undergo extensive migrations from their feeding and nursery areas in the Barents Sea to their spawning areas off the Norwegian coast. During the last $150 \mathrm{yr}$, the NA cod have undergone striking fluctuations in abundance, and also substantial contraction in spawning ground distribution. While the fluctuating stock abundance has received substantial scientific attention (Sætersdal \& Hylen 1964; Garrod 1967; Nakken 1994; Hylen 2002; Godø 2003; Hjermann et al. 2004), there has been little focus on the long-term truncation of spawning ground distribution.

Norwegian Fisheries Statistics (Anon. 1866-1899, $1900-1976$ ) show that until the 1930 s yearly commercial landings of NA cod were registered along the entire West Coast of Norway, from Finnmark to Vest-Agder (figure 1). From the mid-1920s the latitudinal range of spawning grounds has steadily decreased, with

progressively less migration to more southerly spawning grounds. The reasons for the past widespread distribution of spawning grounds are poorly known, and few studies have addressed the issue.

However, recent northward shifts in the spawning ground of Lofoten have attracted popular as well as scientific attention (Jørgensen et al. 2008; Sundby \& Nakken 2008). Sundby \& Nakken (2008) argue that sea temperatures and spawning ground distributions are correlated, indicating that recent northward shifts in the Lofoten spawning ground are caused by climate warming.

Considering the energetic cost of migration, it is plausible that longer migrations provide a reward in terms of fitness. Jørgensen et al. (2008) assumed a linear increase in fitness benefits with decreasing latitudes. From a state-dependent optimization model, they suggest that spawning migration distance is strongly related to body size and physiological state, implying that larger fish and fish in better condition prior to the migration will profit from longer southbound spawning migrations. Smaller fish and fish in poorer condition have a lower fecundity, and would not receive the same fitness gain by longer migration (Jørgensen et al. 2008). A possible fitness benefit could be retention within favourable environments above certain spawning banks further south (Opdal et al. 2008), prolonging the larva's exposure to warmer waters, and thus faster growth (Folkvord 2005). In turn, fast growth commonly leads to reduction in offspring mortality rates (Houde 1989).

It is thought that after the onset of trawl fisheries in the Barents Sea in the 1920s (Sætersdal \& Hylen 1964; Godø 2003), age and body size of the spawning stock has decreased (Jørgensen 1990), possibly leaving a spawning biomass comprised of smaller individuals destined to shorter spawning migrations (Jørgensen et al. 2008).

In this study I present catch data for NA cod from 1866 to 1969 both from spawning ground fisheries and offshore fisheries, providing evidence that the northwards truncation of the NA cod's spawning ground distribution could be caused by a size-selective trawl fishery in the Barents Sea.

\section{MATERIAL AND METHODS}

The commercial catch data for the NA cod (1866-1969) are found in the yearly publications of 'Fisheries of Norway' (Anon. 1866-1899, 1900-1976), originally recorded by the Supervisor of the Lofoten Fishery and county governors along the entire West Coast of Norway. After 1969 the fisheries' statistics no longer distinguish between the NA cod and the coastal cod landings, thus catch data beyond this year are not included in the study. Landings for Finnmark are only available after 1907, as the statistics did not separate between the spawning ground fisheries in the winter and the spring/summer fishery for NA cod feeding on capelin before this. After Norway's involvement in World War II, from 1941 to 1945 , there were considerable restrictions to the fisheries, particularly in the north, and data from this period should be treated accordingly. It is reasonable to assume that for the years before and after World War II the recorded catch statistics are strongly associated with the actual fish abundance. There have been no management restrictions on the coastal fisheries in the studied time period (Anon. 1866-1899, 1900-1976), and there is no reason to believe that certain areas have experienced disproportionate changes in fishing effort relative to other areas.

Throughout the time series, catch data are organized by county, and then by district within each county. In the first period (1866-1937) catches were recorded as numbers of individuals, though from 1905 and onwards catches from Troms and Finnmark 


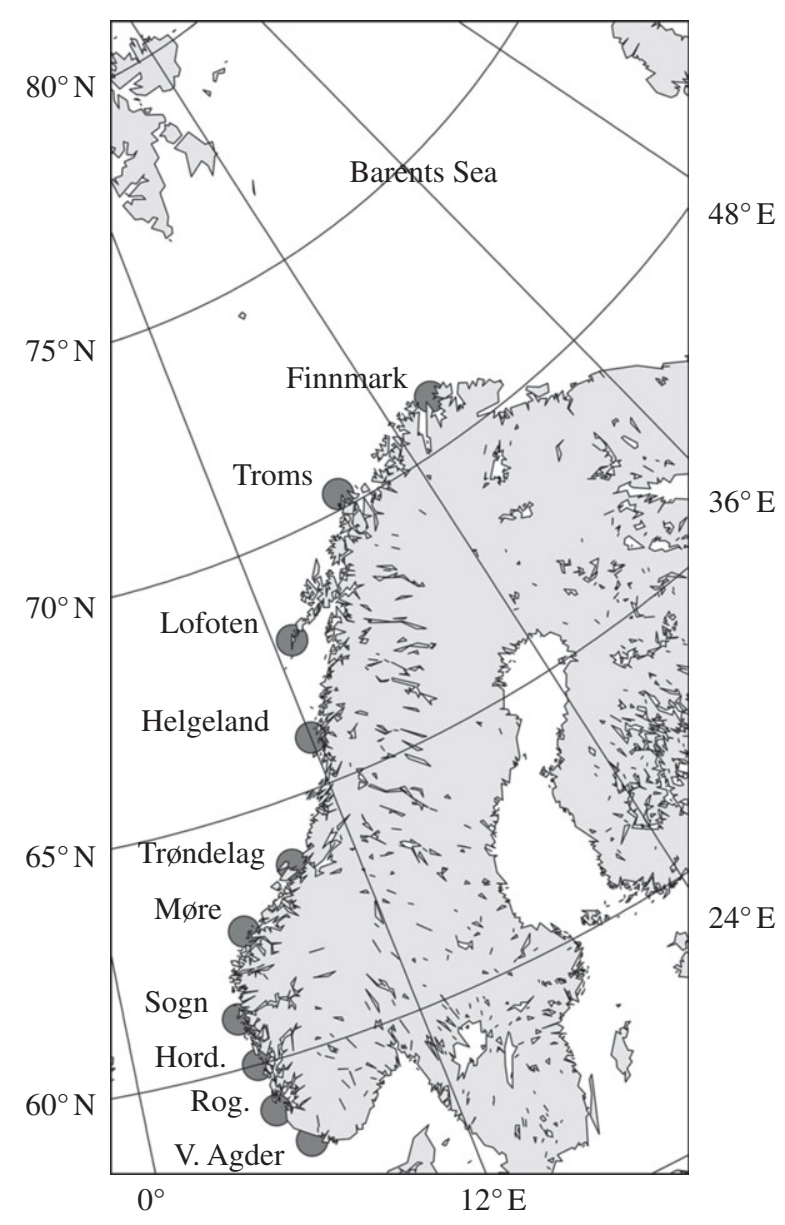

Figure 1. Map indicating the approximate midpoint of each spawning area along the Norwegian coast (adapted from Jørgensen et al. (2008)).

were noted as gutted weight. This refers to the fish wet weight excluding head and intestines. After 1937, gutted weight was used for all counties. In an overlapping period of 8 yr (1929-1937) catch data were presented as both gutted weight and numbers of individuals. Numbers of individuals are converted to gutted weight by extrapolating along the linear regression line between numbers and gutted weight during the overlapping period (1929-1937). All regressions are highly significant with $r^{2}>0.90$ and $p$-values $<$ 0.01 . The landings are assigned to their respective counties-from north to south (figure 1).

All catch statistics for the Barents Sea are extracted as total landed gutted weight (tons) from the official Norwegian catch statistics (Anon. 1900-1976).

To test the effect of the climatic periods (Godø 2003) and the presence of the Barents Sea fishery (BSF) on the spawning ground distribution, a simple analysis of variance (ANOVA) on the relative contribution of catches south of Lofoten was performed.

\section{RESULTS}

It is evident that the spawning grounds used by the NA cod have changed markedly through the years, and that Lofoten remains the single most important spawning area for the NA cod throughout the time period, with the exception of the years around 1915 when the Lofoten catches were exceeded by the total catch from spawning areas south of Lofoten (figure 2). Catches south of Lofoten drop below the historical average in the mid-1920s shortly after an abrupt, sixfold increase in total catch caused by the onset of trawl fisheries in the Barents Sea in 1923. The fisheries south of Møre ceased around 1938, along with a rapid decline in the Møre fishery. From the late-1930s and onwards, catches south of Lofoten are generally low, while simultaneously increasing in the northernmost areas, Troms and Finnmark. After the onset of the BSF, the relative contribution in the south decreased 13 per cent on average (ANOVA, $p>0.05$ ), while during cold climatic periods the relative contribution increased 10 per cent (ANOVA, $p>$ 0.05). By including an interaction between climatic periods and the presence of BSF in the model, the effect of climate during times of BSF becomes negligible (0.4\%; ANOVA, $p>0.05)$.

\section{DISCUSSION}

The spawning distribution of NA cod along the Norwegian coast has been highly variable during the period 1866-1969, and through time the proportion of total catches in the spawning ground fisheries have been increasing in the north and decreasing in the south.

Observation of the fluctuating spawning distribution is not new. Sætersdal \& Hylen (1964) noticed the rapid decline in catches on the southern spawning grounds in the 1920s and stated that the southern NA cod fishery had been insignificant since the 1930s. They argued that the decline was not caused by reduced effort, but rather a natural change in the spawning ground distribution. More recently, Sundby \& Nakken (2008) studied the shifts in spawning ground distribution between Finnmark and Møre during the time period 1905-1969. They correlated smoothed sea temperature and the NA cod's roe indices, and suggested that spawning ground distribution is climate-driven, and that warm periods favour more northbound spawning compared with cold periods.

However, the present study demonstrates that there is also a strong effect of fishery on the spawning ground distribution, and that after the onset of the BSF the influence of the climatic periods is undetectable. The severe truncation of spawning ground distribution after the mid-1920s appears to take place just after the onset of the trawling fishery in the Barents Sea. The trawl fishery in the Barents Sea has a sigmoid selection curve causing higher fishing mortality for the larger individuals, contrary to the traditional line and gill net fishery taking place at the spawning grounds (Huse et al. 2000). Over some time this may have truncated the size distribution of NA cod, and influenced the relative abundance of spawners along the large latitudinal gradient of alternative spawning grounds. This hypothesis is supported by a recent state-variable modelling experiment, predicting that larger and older NA cod in better condition should perform longer migrations than individuals in relatively poorer condition (Jørgensen et al. 2008). Also, we have released and tracked particles in a general circulation model simulating the fate of larvae spawned at different known spawning areas for NA cod (Opdal et al. 2008). This model demonstrated that spawning grounds further south provide better offspring conditions in terms of favourable temperatures and retention schemes. 


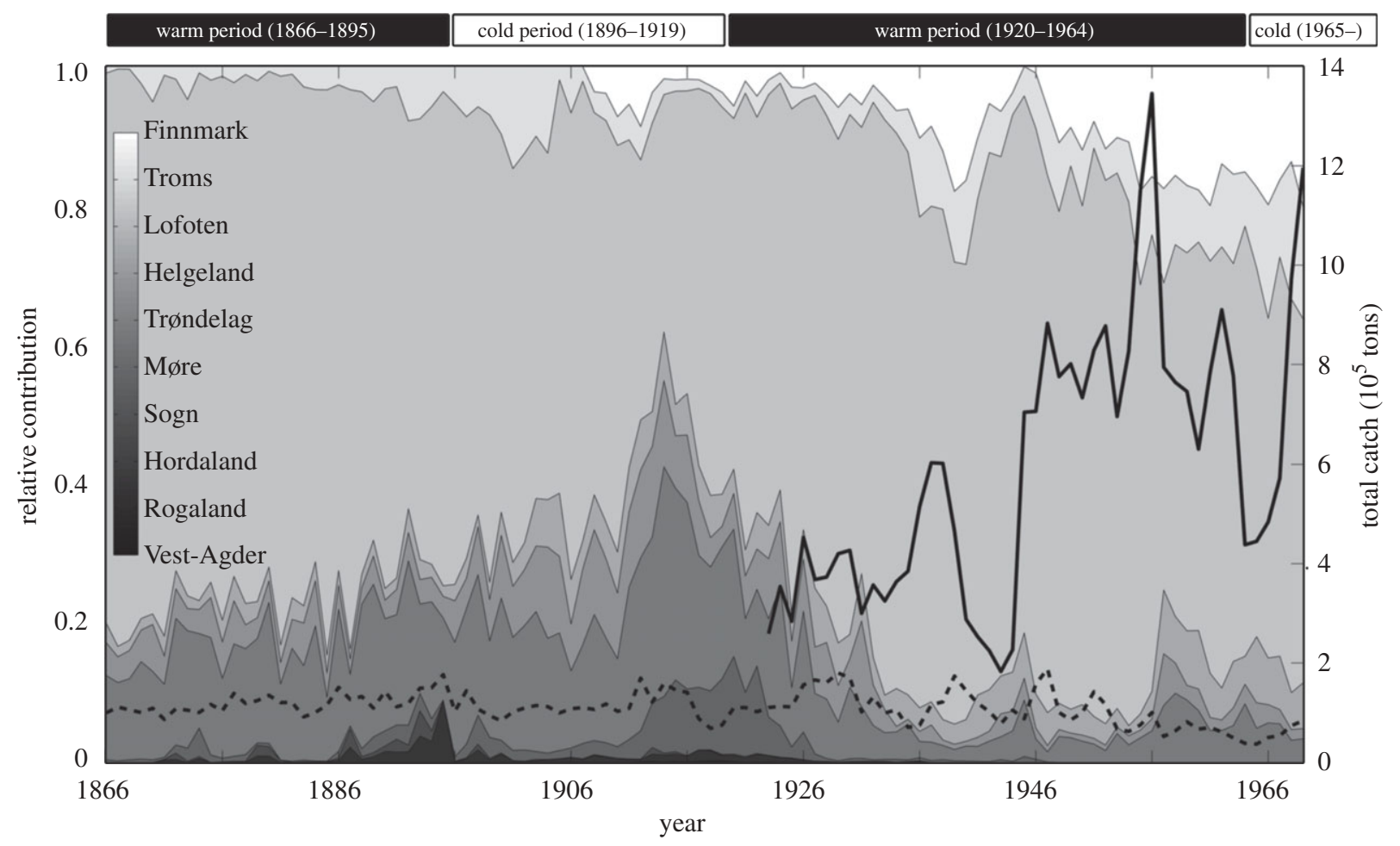

Figure 2. The proportion of the total catch of northeast Arctic cod caught at the different spawning grounds along the coast. The shaded areas represent the relative contribution from each spawning ground to the total catch from the spawning grounds, and are stacked on top of each other from south in Vest-Agder (bottom, black) to north in Finnmark (top, white). The hatched black line indicates the total catches from the spawning ground fishery, and the continuous black line indicates the total catches from the offshore trawl fishery in the Barents Sea, starting in 1923. The top panels denote the different climatic periods as described in Godø (2003). There is a missing data point for Finnmark in 1945 owing to World War II.

The present study suggests that early trawl fishery in the Barents Sea not only caused a sixfold increase in total fishing mortality within a few years, but also truncated the size distribution of the stock. This in turn reduced the abundance of large individuals in the stock, again causing the decline in, and successive disappearance from, the southern spawning grounds. The hypothesis is supported by our earlier modelling studies, and by the time-series data presented here.

Truncation and northward shift in spawning grounds has heavily reduced the latitudinal range of offspring nursery areas, possibly making recruitment processes less resilient towards climatic changes, and could provide further support for the climate-cod recruitment link that has appeared during the last decades (Ottersen et al. 2006). In the long run, high fishing mortalities will also increase allocation to reproduction, and reduce allocation to migration (Jørgensen et al. 2008).

Thanks to Øyvind Fiksen and Knut Wiik Vollset for comments and discussions, and to Loïc Baulier and Agurtzane Urtizberea for statistical advice. Olav Rune Godø is thanked for providing catch data for the Barents Sea.

Anon. 1866-1899 Norges Fiskerier. In Norges officielle statistik (ed. Fisheries Do). Oslo, Norway: Departementet for det Indre/Det Statistiske Centralbureau (from 1875).

Anon. 1900-1976 Norges Fiskerier In Norges officielle statistik (ed. Fisheries Do). Oslo, Norway: Det Statistiske Centralbureau/Fiskeridirektoratet (from 1905).
Folkvord, A. 2005 Comparison of size-at-age of larval Atlantic cod (Gadus morhua) from different populations based on size- and temperature-dependent growth models. Can. f. Fish. Aquat. Sci. 62, 1037-1052. (doi:10.1139/f05-008)

Garrod, D. J. 1967 Population dynamics of Arcto-Norwegian cod. F. Fish. Res. Board. Can. 24, 145-190.

Godø, O. R. 2003 Fluctuation in stock properties of northeast Arctic cod related to long-term environmental changes. Fish Fish. 4, 121-137.

Hjermann, D. O., Stenseth, N. C. \& Ottersen, G. 2004 The population dynamics of northeast Arctic cod (Gadus morhua) through two decades: an analysis based on survey data. Can. F. Fish. Aquat. Sci. 61, 1747-1755. (doi:10.1139/f04-115)

Houde, E. D. 1989 Comparative growth, mortality, and energetics of marine fish larvae - temperature and implied latitudinal effects. Fish. Bull. 87, 471-495.

Huse, I., Løkkeborg, S. \& Soldal, A. V. 2000 Relative selectivity in trawl, longline and gillnet fisheries for cod and haddock. ICES f. Mar. Sci. 57, 1271-1282. (doi:10. $1006 /$ jmsc.2000.0813)

Hylen, A. 2002 Fluctuations in abundance of northeast Arctic cod during the 20th century. ICES Mar. Sci. Symp. 215, 534-550.

Jørgensen, T. 1990 Long-term changes in age at sexual maturity of Northeast Arctic cod (Gadus-morhua L.). 7. Conseil. 46, 235-248.

Jørgensen, C. et al. 2007 Ecology: managing evolving fish stocks. Science 318, 1247-1248. (doi:10.1126/science. 1148089)

Jørgensen, C., Dunlop, E. S., Opdal, A. F. \& Fiksen, Ø. 2008 The evolution of spawning migrations: state dependence and fishing-induced changes. Ecology 89, 3436-3448. (doi:10.1890/07-1469.1) 
Nakken, O. 1994 Causes of trends and fluctuations in the Arcto-Norwegian cod stock. ICES Mar. Sci. Symp. 198, 212-228.

Opdal, A. F., Vikebø, F. \& Fiksen, Ø. 2008 Relationships between spawning ground identity, latitude and early life thermal exposure in northeast Arctic cod. F. Northwest Atl. Fish. Sci. 49, 13-22. (doi:10.2960/J.v41.m621)

Ottersen, G., Hjermann, D. O. \& Stenseth, N. C. 2006 Changes in spawning stock structure strengthen the link between climate and recruitment in a heavily fished cod (Gadus morhua) stock. Fish. Oceanogr. 15, 230-243. (doi:10.1111/j.1365-2419.2006.00404.x)
Sætersdal, G. \& Hylen, A. 1964 The decline of the skrei fisheries. Rep. Norweg. Fish. Mar. Invest. 13, 58-69.

Sundby, S. \& Nakken, O. 2008 Spatial shifts in spawning habitats of Arcto-Norwegian cod related to multidecadal climate oscillations and climate change. ICES 7. Mar. Sci. 65, 953-962. (doi:10.1093/icesjms/ fsn085)

Walther, G. R., Post, E., Convey, P., Menzel, A., Parmesan, C., Beebee, T. J. C., Fromentin, J. M., Hoegh-Guldberg, O. \& Bairlein, F. 2002 Ecological responses to recent climate change. Nature 416, 389-395. (doi:10.1038/ 416389a) 